\title{
Is L2 Exposure Always a Strong Modulator of L1 Influence? Evidence from Chinese EFL Learners Acquiring English Collocations
}

\author{
Hanzhong Sun $^{1}$ \\ ${ }^{1}$ College of Foreign Languages, Quzhou University, Zhejiang, China \\ Correspondence: Hanzhong Sun, College of Foreign Languages, Quzhou University, Zhejiang, China. E-mail: \\ sunhanzhong@foxmail.com
}

Received: May 16, 2020

Accepted: June 17, $2020 \quad$ Online Published: June 23, 2020

doi:10.5539/ijel.v10n5p23

URL: https://doi.org/10.5539/ijel.v10n5p23

\begin{abstract}
Despite the voluminous body of research investigating the role of L1 influence in acquiring L2 collocations, research that examines the extent to which L2 exposure modulates L1 influence is relatively scant. The present study, therefore, aims to address this under-studied issue. To this end, two types of collocations comprising congruent collocations (i.e., collocations which have literal translation equivalents in learners' L1) and non-congruent collocations (i.e., collocations that do not have L1 literal translation) were used as materials to elicit the potential role of L1 in acquiring L2 collocations. A blank-filling collocation test and an acceptability judgement collocation test were designed and then administered to three groups of Chinese EFL learners differing in L2 exposure, i.e., years of instructions (freshmen, sophomores and juniors), affording the chance to explore the possible relationship between L1 influence and L2 exposure. The findings indicate that (a) L1 had a robust and persistent impact on acquiring L2 collocations at both reception and production level, regardless of the amount of L2 exposure received; (b) with an increase in L2 exposure, receptive/productive congruent and non-congruent collocational knowledge was developed in parallel (from freshman to sophomore), and then plateaued or even decreased (from sophomore to junior), suggesting that L2 exposure may not always be a strong modulator of L1 influence. Possible reasons and pedagogical implications arising from this study are discussed.
\end{abstract}

Keywords: congruent collocation, non-congruent collocation, L1 influence, L2 exposure, reception and production

\section{Introduction}

It is well-established that vocabulary constitutes an indispensable part of language learning. As a part of vocabulary, collocations have also received considerable attention from researchers. For one thing, collocations are ubiquitous in natural language use (Howarth, 1996; Kjellmer, 1987), and for another, the use of collocations can significantly improve the fluency and nativelikeness of oral and written production (Ellis, 1996; Wood, 2006; Huang, 2015). However, collocations still present an enormous challenge even to advanced learners (MaCarthy, 1990; Bahns \& Eldaw, 1993; Laufer \& Waldman, 2011). Previous studies have suggested numerous influencing factors, interlexical or intralexical, that hinder the acquisition of L2 collocations (Peters, 2015). Among those factors, L1 influence has been widely acknowledged and thus triggered the interest of many researchers (Nesselhauf, 2003; Shehata, 2008; Yamashita \& Jiang, 2010; Laufer \& Waldman, 2011; Wang, 2011; Xu \& Wang, 2015; Peters, 2015; Peng \& Wang, 2016, Sun, 2018).

Most of these studies were conducted using two or more groups of learners differing in L2 proficiency or in learning setting (EFL/ESL) to substantiate the involvement of L1 in acquiring collocations. However, this grouping method did not allow for capturing the gradual change of L1 influence on the acquisition of L2 collocations in a more subtle manner. Based on this concern, the present study sets out to examine the influence of L1 on the acquisition of L2 collocations among three groups of Chinese EFL learners receiving different amounts of L2 exposure, to further track the refined change of L1 influence on L2 collocation acquisition. In other words, the purpose of this study is to explore the relationship between L1 influence and L2 exposure. 


\section{Literature Review}

\subsection{Definition and Classification of Collocation}

\subsubsection{Definition of Collocation}

Although collocations have been extensively studied, no consensus has been reached concerning the exact definition of collocation. Generally speaking, there are two main approaches that have been adopted to identify collocation, i.e., frequency-based approach and phraseological approach. Firth (1957), as an advocate of the former approach, viewed collocations as a combination of two or more actual words in habitual company, and these words were not simply placed together, but rather, they were mutually expected. Under this approach, frequency has the final say in determining whether or not a word combination is a collocation.

Other scholars attempted to perceive collocations in a phraseological approach and they focused on the intrinsic linguistic properties, such as structure and semantics, of collocations. Cowie (2002) maintained that collocations were regarded as ready-made, memorized word groups, in which one word had a certain meaning only in combination with the other word, or with very few similar words. For example, heavy means being huge or big on the condition that it is collocated with such words as rain, snow and so on.

The current study follows the phraseological approach, treating collocation as word units that are grammatically well-formed and semantically or arbitrarily restricted. The rationale for this selection is that the semantic factor, i.e., L1-L2 congruence, is taken into consideration.

\subsubsection{Classification of Collocation}

Since collocation is an umbrella term, there are no fixed ways to classify it. The most widely accepted one was initiated by Benson, Benson and Ilson (1986). From their perspective, collocations fall into two categories: lexical collocations and grammatical collocations (Benson et al., 1986). In terms of the dominant word, collocation can be grouped into noun collocations, verb collocations, adjective collocations and so on.

For L2 learners, collocations can also be categorized into congruent collocations and non-congruent collocations, in terms of whether the meaning and structure are matched between their L1 and L2, or simply, L1-L2 congruence (Nesselhauf, 2003). Congruent collocations refer to those that have literal translation equivalents in learners' L1. By contrast, non-congruent collocations do not have L1 translation equivalents. For instance, to Chinese learners, make a decision can be seen as a congruent collocation, because make and decision literally correspond to the Chinese translation zuo and jueding, while weak tea is a non-congruent collocation, for the reason that the meaning of this collocation dancha cannot be deduced from its component words weak and tea.

\subsection{Empirical Studies on L1 Influence on the Acquisition of L2 Collocation}

Recently there has been a growing body of research investigating the role of L1 in acquiring L2 collocations. Roughly speaking, collocations have been studied from three research lines, namely, phraseology (Nesselhauf, 2003), corpus linguistics (Sun, 2004; Laufer \& Waldman, 2011; Zheng \& Xiao, 2015) and psycholinguistic methods (Caroli, 1998; Elyildirm, 1998; Gitsaki, 1999; Shehata, 2008; Liao, 2010; Wang, 2011; Xu \& Wang, 2015; Peng \& Wang, 2016; Sun \& Chen, 2017; Sun, 2018). Despite the employment of different methods, L1 influence has been reported to exist in the acquisition of L2 collocations. In the following part, I will review related empirical studies from these three strands.

Nesselhauf (2003) reported on a study of collocations in a phraseological sense. He analyzed the use of verb-noun collocations, which were selected in terms of restrictions on substitutability, by advanced German learners of English in a free writing task. Various methods were employed to judge the acceptability of the chosen collocations, such as dictionaries, British National Corpus and intuitive judgments of native speakers. The results revealed that the $\mathrm{L} 1$ of the learners seemed to play a fairly important role in the production of mistaken verbs, such as make one's homework and take one's task.

With the advent of computational science and corpora, some researchers began to resort to corpora to investigate collocations (Sun, 2004; Laufer \& Waldman, 2011; Zhang \& Xiao, 2015). For instance, Laufer and Waldman (2011) investigated the use of English verb-noun collocations produced in a writing task by Hebrew learners of different English proficiency levels. They built a learner corpus that consisted of augmentative and descriptive essays composed by the learners, and chose a native speaker corpus for comparison purposes. They then retrieved verb-noun collocations from the two corpora, and two comparisons were performed: learners were compared with native speakers on the frequency of collocation use and learners were compared with other learners of different L2 proficiency levels on the frequency and correct use of collocations. The findings indicated collocation use was a big stumbling block even for advanced learners, which was revealed by the 
persistence of L1-based errors. Likewise, Sun (2004) made a contrastive study on the adjective-noun collocations in Chinese EFL context. The research was based on two qualitatively distinct types of corpora, namely, a learner corpus and an English corpus of native speakers. She picked eight target words as node words and identified corresponding collocations. Huge differences were found between Chinese learners' use of adjective-noun collocations and the authentic use by native speakers. She resorted to L1 influence as one of the factors to account for the inadequate acquisition of collocations by the learners. For example, big hope, as mentioned in her study, was one of the errors the Chinese learners often made. Along the similar line, Zhang and Xiao (2015) analyzed the use of collocations in oral production by Chinese EFL learners. When using verb-noun collocations, the learners had a great difficulty in using the verbs. L1 transfer was also identified as one of the causes responsible for the existence of verb-noun collocation errors.

Collocations have also been approached in psycholinguistic experiments. Elyildirm (1998) used offline methods to confirm the influence of L1 on the comprehension and production of verb/adjective-noun collocations in English by Turkish learners. The participants in the study were administered into three collocation tests, including acceptability test, translation test and gap-filling test. The results showed that the learners tended to overgeneralize the unfamiliar collocations by using their known L1 knowledge, and also it confirmed the relative ease of congruent collocations and the difficulty of acquiring non-congruent collocations. The results were replicated by subsequent studies using learners of different backgrounds (Caroli, 1998; Shehata, 2008; Liao, 2010; Wei, 2014; Peng \& Wang, 2016; Sun \& Chen, 2017; Sun, 2018). Similar to what previous studies have found, Liao (2010) investigated positive and negative cross-linguistic transfer on the phraseological competence of Chinese EFL learners, and two instruments, which included test items composed of de-lexicalized verbs, such as $d o$, have, make and take, and nouns, were administered to the subjects from three proficiency groups. One of her findings showed that the phraseological competence of the learners was significantly influenced by L1-L2 congruence effect.

\subsection{Empirical Studies on L1 Influence and L2 Overall Proficiency/Exposure}

A few studies have been dedicated to the exploration of the relationship between L1 influence and L2 general proficiency level/exposure. For example, Peng and Wang (2016) aimed to examine the effect of L1 influence, L2 proficiency and collocation type on the acquisition of English collocations by Chinese EFL learners. A pen-and-pencil immediate acceptability judgment test was administered into two groups differing in L2 proficiency. The results showed learners with higher proficiency responded to congruent and non-congruent more accurately, which suggested strong positive influence and weak negative influence on congruent collocation and non-congruent collocations respectively. By adopting a similar acceptability judgement test of collocations, Sun (2018) investigated the acquisition and development of L2 congruent and non-congruent collocations among Chinese EFL learners in different academic levels, and it also revealed the constant involvement of L1 in acquiring L2 collocations, regardless of what academic stage the participants were at.

Apart from delving into collocations by employing the traditional pen-and-pencil methods, researchers have also utilized online processing methods to explore this issue (Yamashita \& Jiang, 2010; Wolter \& Yamashita, 2014). For example, Yamashita and Jiang (2010) explored the influence of learning setting (ESL/EFL) and L1 on processing L2 verb-noun and adjective-noun collocations. The subjects, including Japanese EFL/ESL learners, and English native speakers as a baseline group, were compared on the performances of congruent collocations and non-congruent collocations in an online immediate acceptability judgment task. The results exhibited that compared with congruent collocations, the learners responded more slowly to and made more errors in non-congruent collocations, and perhaps more importantly, ESL learners responded to congruent/non-congruent collocations faster with a higher accuracy rate than the EFL counterparts.

Taken together, these research findings reviewed above indicate that L1 exerts an influence on the acquisition of $\mathrm{L} 2$ collocations, and with increasing in exposure to L2, the influence of $\mathrm{L} 1$ tends to change.

\subsection{Summary and Aim of the Present Study}

The literature reviewed above mainly focuses on empirical studies that used two or more groups in terms of the learners' L2 proficiency (e.g., low level, intermediate level), or their learning settings (i.e., EFL and ESL), and have yielded fruitful pedagogical implications, suggesting that the acquisition of L2 collocations is influenced by learners' L1, and with the improvement of L2 proficiency and a shift in learning context from EFL to ESL, L1 influence will change accordingly.

However, given that language learning should potentially be a slow and progressive process, the way the participants were grouped in previous studies did not allow for the detection of the gradual change in L1 influence, with the exception of Sun (2018), who claimed to investigate the collocation behavior of four groups 
of learners receiving different amounts of L2 exposure. Therefore, to better capture the change of L1 influence, three or more groups in the same learning context, either EFL or ESL, should be considered, and the factor of L2 exposure should also be included. Although some studies examined the effect of L2 exposure on L2 collocations (Tan, 2006; Ganji, 2012), they investigated the overall collocation knowledge and overlooked the role of L1. To the best of my knowledge, only a limited number of studies have been reported to explore how L1 influence and L2 exposure affect the learning of L2 collocations in a single study. Sun (2018) investigated the L1 influence on L2 collocation acquisition among learners with different L2 exposure, instead of L2 proficiency levels, but this study suffers from two limitations. Firstly, no significance test was actually run to check whether the four groups of participants, though at different academic levels, i.e., freshman, sophomore, junior and senior, received different periods of instructions (L2 exposure). And secondly, it was examined only at reception level, and it remains to be seen whether the results equally apply at production level.

Therefore, the main focus of the present work is on whether the learners' L1 influences the acquisition of L2 collocations at both reception and production level, and if so, whether L2 exposure is always a strong modulator of L1 influence. To address the first research question, congruent collocations and non-congruent ones will be compared. If congruent collocations are performed better than their non-congruent counterparts, L1 will be confirmed as an important role in the acquisition of L2 collocations. The second research question necessitates the comparisons across three groups of learners in four types of collocations separately. With an increase to L2 exposure, the better congruent and noncongruent collocation performances can be taken as evidence of stronger L1 positive influence and weaker L1 negative influence respectively, i.e. L2 exposure is a strong modulator of L1 influence in this case.

\section{Method}

\subsection{Participants}

The participants recruited for this study were one hundred and two Chinese EFL students majoring in English Education. They attended the same university, but came from three different academic levels, i.e., freshman, sophomore and junior. Among them, eleven of them did not complete the whole experiment, so all of their reported information and data were removed from further analysis. Besides, nine sophomores were also excluded, because they transferred from other majors. This was to minimize the possible effects of such external factors as prior learning background, thus ensuring the homogeneity of the participants across these three academic levels. Eighty-two students were retained, comprising thirty-two freshmen (two males), twenty-five sophomores (three males) and twenty-five juniors (three male).

All of the participants were native speakers of Chinese and they have been learning English as their second (foreign) language mainly at classroom settings. At the time of being tested in the present study, none of them had any experiences of studying in English-speaking countries, even for a short period of time. They ranged in age from 19 to 23 , and their received formal instructions ranged from 7 years to 15 years. The descriptive statistics is presented in Table 1. To further determine whether there were differences in years of instructions (L2 exposure) among the three groups, a one-way ANOVA was conducted and the results indicated that the differences reached a significant level $(\mathrm{F}(2,79)=18.35, p<0.001)$. Multiple comparison tests were then run to check where the differences lied. These tests revealed that differences existed in all three pairs (freshman-sophomore, fresh-junior and sophomore-junior) $(p<0.05)$. Therefore, the students in junior group received the longest period of instructions (12.64), followed by sophomores (11.72) and freshmen (10.56) successively.

Table 1. Descriptive statistics of the years of English formal instructions (L2 exposure)

\begin{tabular}{llllll}
\hline Group & N & Min & Max & M & SD \\
\hline Freshman & 32 & 7 & 13 & 10.56 & 1.52 \\
Sophomore & 25 & 8 & 13 & 11.72 & 0.89 \\
Junior & 25 & 9 & 15 & 12.64 & 1.32 \\
\hline
\end{tabular}

\subsection{Materials}

The target collocations investigated in this study were two common types of lexical collocations, namely, verb-noun collocations and adjective-noun collocations. There were two reasons for the selection of these two types. Firstly, according to the analytic data from Chinese Learner English Corpus (CLEC), Chinese learners tend to commit much more errors in these two types, compared to other types. Secondly, these two types of 
collocations were proven to be vulnerable to L1 transfer by previous studies (Elyildirm, 1998; Nessulhauf, 2003; Yamashita \& Jiang, 2010). Therefore, they deserved our extra attention.

To serve the purpose of the present study, half of target items were congruent collocations which had literal translation equivalents in learners' L1, while the other half were non-congruent collocations, i.e., collocations that did not have L1 literal translation. The following procedures were strictly obeyed in selecting the target items. Firstly, 40 collocations were drawn from previous studies (Shehata, 2008; Sun \& Chen, 2017; Sun, 2018). Then, three graduate students majoring in applied linguistics were invited to make an judgement as to whether or not each of the 40 collocation were congruent between English and Chinese, on a scale of 1 to 3 (" 1 " means that "the collocation was not congruent", "2" means "not sure", and "3" represents "congruent collocation"). Subsequently, items that were scored " 2 " by any of the three students were jettisoned, and the others were kept. As a result, 18 congruent collocations and 16 non-congruent collocations were selected.

Since the test was designed to elicit the influence of L1 knowledge on the acquisition of L2 collocations, there was no need to include any unfamiliar words the learners might be struggling with. I asked two high school teachers who taught English to evaluate whether the component words in these 34 collocations might be familiar to high school students. The aim of this step was to rule out the possibility that the participants might fail to recognize these component words due to their unfamiliarity with these words, which resulted in the final selection of 24 target items, including 6 verb-noun congruent collocations, 6 verb-noun non-congruent collocations, 6 adjective-noun congruent collocations and 6 adjective-noun non-congruent collocations (The complete list of the target items can be seen in Appendix A).

\subsection{Instrument}

Researchers have devised a variety of instruments to measure learners' knowledge of collocations, such as multiple choice (Bonk, 2000; Wang, 2011), acceptability judgment (Li, 2013; Peng \& Wang, 2016), blank-filling (Wang, 2011; Wei, 2014), translation (Elyildirm, 1998; Chen, 2004), free essay writing (Gitsaki, 1999; Nesselhauf, 2003). All of these tests can be boiled down to two types: receptive test and productive test. Accordingly, there are two kinds of collocational knowledge. Receptive knowledge of collocations, often measured by acceptability judgment test and multiple choice in previous research, refers to the type of collocations the learners need to understand certain materials, whereas productive knowledge of collocations, measured by translation, blank-filling and essay writing, points to the type of collocations allowing the learners to use in their writing or speech. Most studies tend to include two or more tests to elicit both receptive and productive knowledge of collocations (Gitsaki, 1999; Chen, 2004; Shehata, 2008; Liao, 2010; Li, 2013; Sun \& Chen, 2017).

\subsubsection{Acceptability Judgement Test}

An acceptability judgement test was designed to measure the receptive collocation knowledge of the participants, in which the participants were asked to judge whether the collocations were acceptable. There are several steps involved in the construction of the test.

Firstly, twenty-four sentences containing the target collocations were constructed. Each target collocation was embedded in one sentence context, which can hopefully increase eco-validity of the instruments. Longman Dictionary of Contemporary English (2009) was then consulted for their translation to Chinese, with which they might have a better understanding of the collocations.

Then, in order to elicit different responses from the participants, some modifications were made to the target collocations. Most of the non-congruent collocations were presented with their literal translation. For example, brown sugar was translated into hong tang in Chinese, which literally corresponded to red sugar, so brown sugar was replaced by red sugar to elicit a negative response. All the congruent items were still presented with their correct forms. Consequently, half of the collocations should be given a positive response, while half of the collocations require the participants to make a negative response, that is, to reject the form of those modified but ill-formed collocations.

Thirdly, before this test was finalized, two high school English teachers were invited again to assess the quality of the sentences, such as whether all the words in those sentences were familiar to high school students and whether the sentence structures could be understood by their students. If not, some adjustments were further made, thus ensuring that the participants in this study may not have any difficulty in understanding these sentences.

The participants were asked to judge whether the italicized verbs or adjectives were acceptable by ticking or crossing the box behind the sentences. Three options were given to each test item, that is, "correct", "not sure" 
and "wrong". The option "not sure" was included, in a move to minimize the guessing effect. Two sample test items were provided below. All the test items were randomized. The whole test is attached in Appendix B.

(1) He did very well, but failed to break the record. (打破纪录)

$\square$ Correct $\quad \square$ Not sure $\quad \square$ Incorrect

(2) It is polite to drink soup（喝汤） without making a noise.

$\square$ Correct $\quad \square$ Not sure $\quad \square$ Incorrect

\subsubsection{Blank-Filling Test}

A blank-filling test was devised to elicit the productive knowledge of the target collocations from the participants. These collocations were embedded in different sentences which were also reviewed by two high school English teachers.

For each sentence, the participants were required to supply a certain word according to the given Chinese expressions, which was supposed to be both orthographically and grammatically correct. Again, all the sentences were put in a randomized order. The whole test can be seen in Appendix C. Displayed below are two examples for reference.

(3) Liu Xiang is a famous star, and he the record（打破纪录）for several times.

(4) In China, women often soup (喝汤) after giving birth to a baby, especially chicken soup.

\subsubsection{Word Recognition Test}

In order to ensure the familiarity of the target verbs and adjectives in collocations, participants then completed a word recognition test presented in Appendix D, in which they needed to indicate whether they were familiar with the target words (yes or no).

\subsubsection{Background Information}

The participants were also required to provide some background information (Appendix E), such as their major, age, gender, years of exposure to formal English instructions, and whether they had any previous overseas study experience. These information offers a fuller picture to understand them.

\subsection{Data Collection}

Before the main test was administered, a pilot experiment was implemented to work out the time needed to complete the test. Two students from each academic level (six in total) were randomly chosen. They came from the same population as the participants in the main test, and they did not attend the following main test. It turned out that ten minutes was a proper time span for each of the reception and the production test. Then all of the eight students were asked to do the word recognition task, in which they needed to cross the words that they had no knowledge of. It was revealed that they were all familiar with these verbs and adjectives.

The experiment was conducted where normal class instructions took place. The procedure of the whole experiment is sketched below in Figure 1. Considering reception and production tests shared the same target collocations, the participants completed the production test on the first day, and reception test and other tests on the second day, to avoid contamination effect. To further reduce such effect, extra measures were taken. First, the participants were unaware of another test (acceptability judgement test) the next day. Second, sentence contexts employed in the two tests were different. Third, the target collocations embedded in sentences were presented in completely different order.

\begin{tabular}{|c|c|c|}
\hline \multicolumn{3}{|c|}{ Day one } \\
\hline \multicolumn{3}{|c|}{ Blank-filling test (production) } \\
\hline \multicolumn{3}{|c|}{ Day two } \\
\hline Acceptability judgement test (reception) & Word recognition test & Background information \\
\hline
\end{tabular}

Figure 1. The procedure of the whole experiment

Before the reception and production test papers were handed out, the participants were told that the aim of this test was to test their knowledge about some widely used collocations, and they had to finish it on their own without checking any reference materials or discussing with others. After ten minutes, all test papers were 
collected. One test item was worth one point, so the total score for each test was twenty-four. Only those test items which got correct answers received points.

\subsection{Data Processing}

For each test paper, the sub-score for congruent and non-congruent collocations were typed in an Excel document, and the data were analyzed via SPSS 21.0 software. One-way ANOVA statistical tests and subsequent t-tests were run and the conventional level 0.05 was used to reveal the significance level.

\section{Results}

Mean and SD were computed for each type of collocation knowledge (congruent-reception, noncongruent-reception, congruent-production and noncongruent-production) across three groups of learners by utilizing SPSS software (version 21.0). All of the data was tabulated in Table 2, and then graphically presented in Figure 2.

Table 2. The mean scores (SD) for congruent and non-congruent collocations

\begin{tabular}{lllll}
\hline \multirow{2}{*}{ Group } & Reception Test & \multicolumn{3}{l}{ Production Test } \\
\cline { 2 - 5 } & Congruent & Non-congruent & Congruent & Non-congruent \\
\hline Overall & $11.02(1.10)$ & $6.41(2.63)$ & $10.79(1.40)$ & $6.02(2.37)$ \\
Freshman & $10.72(1.40)$ & $5.13(2.30)$ & $9.56(1.39)$ & $4.00(1.68)$ \\
Sophomore & $11.52(0.51)$ & $7.04(0.51)$ & $11.76(0.44)$ & $7.68(1.63)$ \\
Junior & $10.92(0.95)$ & $7.44(2.81)$ & $11.40(0.76)$ & $6.96(1.84)$ \\
\hline
\end{tabular}

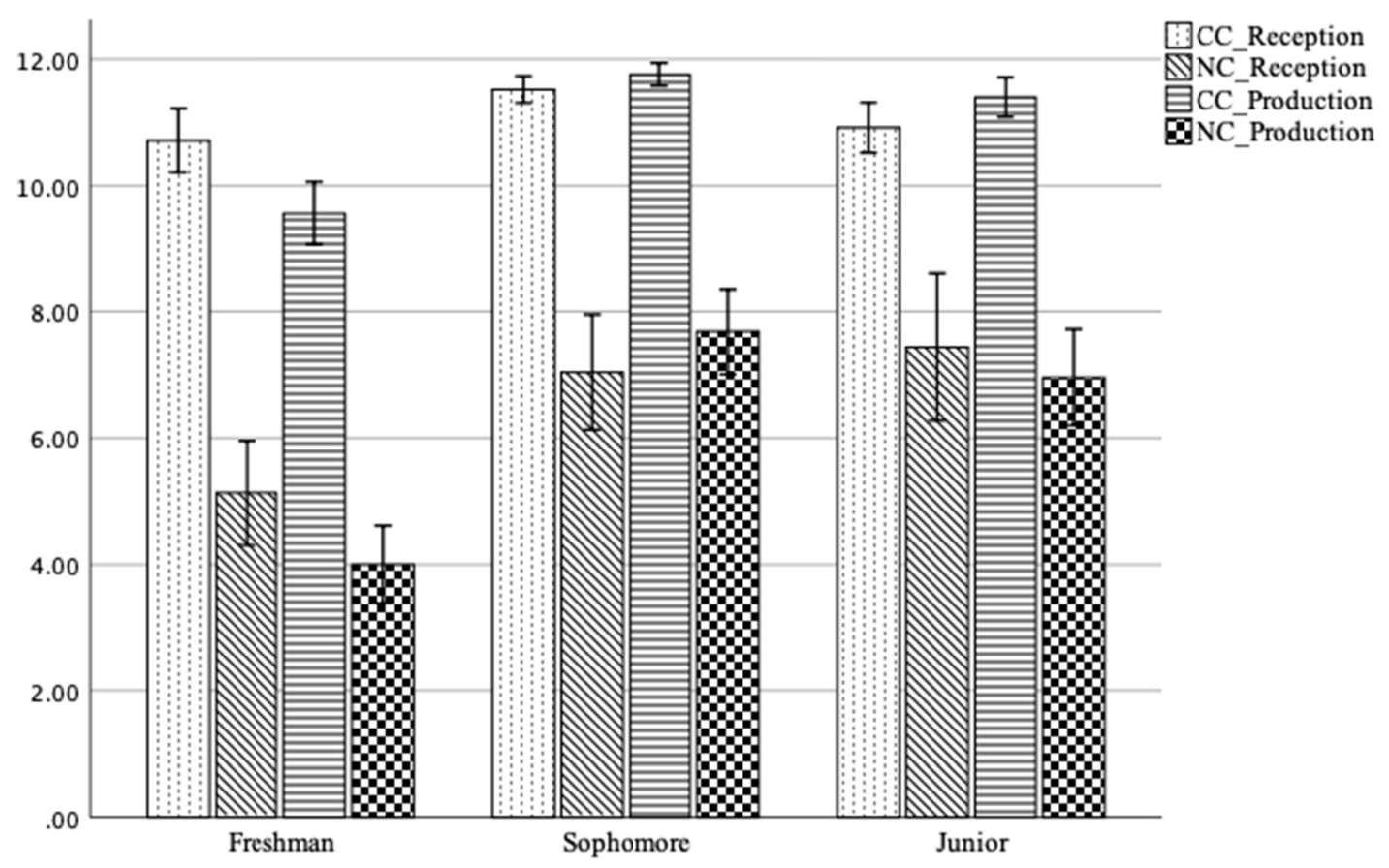

Figure 2. The mean scores for congruent and non-congruent collocations

Note. Error Bars indicate $95 \% \mathrm{CIs}, \mathrm{CC}=$ Congruent Collocation, $\mathrm{NC}=$ Non-congruent Collocation.

\subsection{Research Question One: Does L1 Influence the Use of L2 Collocations at Reception and Production Level?}

In order to probe into the first research question, which attempts to explore the influence of L1 on the reception and production of L2 collocations, the performances on congruent collocations and their non-congruent counterparts were examined and compared. If L1 assumes a certain role, facilitative or hindering, in acquiring L2 collocations, it is expected that the performances on congruent collocations will be better than the performances on non-congruent collocations. An array of paired-sample t-tests were run to confirm the above assumption.

In the reception test, the results showed that the overall performance on congruent collocations were better than that on non-congruent counterparts $(\mathrm{MD}=4.61)$, and the difference was very significant $(p<0.001)$. Then the same t-test was performed at each academic level. The results demonstrated that the score of congruent 
collocations was always higher than that of non-congruent collocations, regardless of the academic level, and the difference was also significant $(p<0.001)$, indicating that the L1 has a persistent effect on L2 collocation acquisition.

In the production test, the same conclusion was reached that congruent collocations were better mastered by the learners, compared with non-congruent collocations $(\mathrm{MD}=4.77)$. Besides, at all academic levels, congruent collocations received much more scores than noncongruent ones $(p<0.001)$.

These significant differences could also be observed from the non-overlapping error bars between congruent and non-congruent collocations shown in Figure 2. Taken together, the learners seem to be more successful with collocations with L1-L2 congruence than with those having no translation equivalents in L1, which gives clear evidence of the existence of $\mathrm{L} 1$ influence.

\subsection{Research Question Two: Is L1 Influence Always Modulated by L2 Exposure?}

Since L1 has a persistent impact on learning L2 collocation, is this impact prone to change with an increasing exposure to L2? In order to answer this question, an array of one-way ANOVA tests was performed.

Firstly, a one-way ANOVA test was conducted on the scores of congruent collocations in the reception test. The findings revealed that the main effect of years of instructions was significant $(\mathrm{F}(2,79)=4.194, p=0.019)$, which meant that there were differences in these three groups of learners. To track down the sources of differences, LSD multiple-comparison tests were carried out, the results of which indicated that differences reached a significance level in freshman-sophomore pair $(p=0.006)$ and in sophomore-junior pair $(p=0.049)$. But there were no differences in freshman-junior $(p=0.478)$. The results suggested that congruent collocation knowledge increased and peaked at sophomore stage (11.52), followed by a slight decline among junior students (10.92).

Next, a similar statistical procedure was performed on non-congruent collocations in the reception test. A main effect on years of instructions were also found $(\mathrm{F}(2,79)=7.494, p=0.001)$. Post-hoc tests showed that both freshman-sophomore and freshman-junior pairs displayed significant increases $\left(p_{1}=0.012, p_{2}=0.002\right)$, but no differences were reported in sophomore-junior pair $(p=0.831)$. Put these together, it was concluded that the collocational knowledge showed an upward increase from freshman (5.13) to sophomore (7.04), but then stabilized at junior stage (7.44).

Then, following the same statistical test, I also found a very significant main effect on congruent collocation knowledge in the production test $(\mathrm{F}(2,79)=40.812, \mathrm{p}<0.0005)$. The scores between freshmen and sophomores, and freshman and juniors reached a significance level $(p<0.0005)$. However, no differences could be revealed between sophomores and juniors $(p=0.412)$. The same changing pattern emerged as the one in non-congruent collocation reception knowledge.

Lastly, I performed the same statistical procedures on the scores of non-congruent collocation in production test. The main effect of years of instructions also appeared $(\mathrm{F}(2,79)=37.656, p<0.0005)$. Differences emerged in freshman-sophomore and freshman-junior pairs $(p<0.0005)$. Still, there were no differences showed between sophomores and juniors $(p=0.304)$.

Table 3 summarizes the changing patterns of the scores across three groups of learners in the four types of collocation knowledge.

Table 3. The changing patterns of the scores across three groups of learners

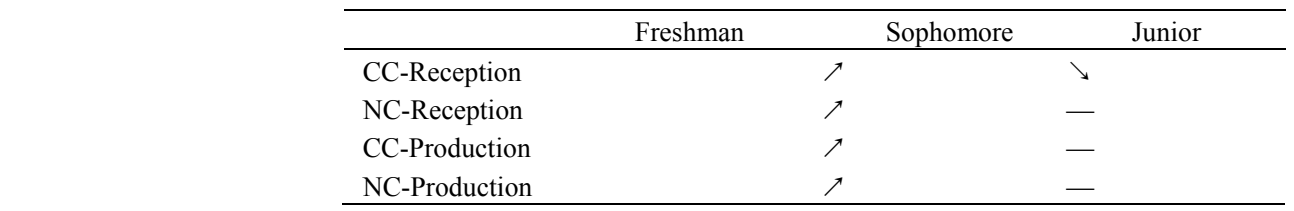

Note. CC- Congruent Collocation, NC-Non-congruent Collocation.

In addition, another way to address the change of $\mathrm{L} 1$ influence is by looking at individual words supplied by the participants in the production test. I selected three collocations, i.e., modern society, acquire knowledge and heavy traffic, to analyze the changing patterns from freshman to junior. The words provided by them were extracted and the proportion of each provided word was computed in Table 4. Special attention was given to some wrong chosen words induced by their L1, which were marked with * symbol. Surprisingly, the participants still made mistakes on modern society, a congruent collocation. Approximately $20 \%$ of them chose other words, 
such as present, today and nowadays. For the other two non-congruent collocations, it is clearly demonstrated that with an increase in L2, L1 negative influence tends to decrease from freshman to sophomore, but later it increases. For example, nearly $68 \%$ of freshmen were prone to L1 negative influence, producing such collocations as busy traffic and crowded traffic, while nearly $50 \%$ of sophomores and $56 \%$ of juniors used busy traffic.

Therefore, it is concluded that with an increase in L2 exposure, L1 influence change firstly from freshman to sophomore, and later remain unchanged from sophomore to junior, generally. Taken together, L2 exposure may not always be a strong modulator of L1 influence.

Table 4. The supplied words in the production test

\begin{tabular}{|c|c|c|c|}
\hline & Freshman $(\mathrm{N}=32)$ & Sophomore $(\mathrm{N}=25)$ & Junior $(\mathrm{N}=25)$ \\
\hline xian & modern society $(34.38 \%)$ & modern society $(100 \%)$ & modern society $(100 \%)$ \\
\hline \multirow[t]{5}{*}{ dai she hui } & *present society $(3.13 \%)$ & & \\
\hline & *nowadays society $(12.5 \%)$ & & \\
\hline & *recent society $(3.13 \%)$ & & \\
\hline & *today's society $(3.13 \%)$ & & \\
\hline & others: new, social, model $(43.77 \%)$ & & \\
\hline xue & *study knowledge $(9.38 \%)$ & acquire knowledge (36\%) & acquire knowledge (16\%) \\
\hline$x i$ & *learn knowledge (87.5\%) & *study knowledge (4\%) & *study knowledge (24\%) \\
\hline$z h i$ & blank $(3.13 \%)$ & *learn knowledge $(56 \%)$ & *learn knowledge $(56 \%)$ \\
\hline shi & & take knowledge $(4 \%)$ & take knowledge $(4 \%)$ \\
\hline fan & heavy traffic $(28.13 \%)$ & heavy traffic $(52 \%)$ & heavy traffic $(40 \%)$ \\
\hline mang de & *busy traffic $(53.13 \%)$ & *busy traffic $(48 \%)$ & $*$ busy traffic $(56 \%)$ \\
\hline jiao & *crowded traffic $(15.63 \%)$ & & blank $(4 \%)$ \\
\hline tong & blank $(3.13 \%)$ & & \\
\hline
\end{tabular}

Note. *indicates L1-induced wrong collocations.

\section{Discussion}

The current research examined L1 influence on the acquisition of L2 collocations across three groups of learners receiving different periods of instructions to track the gradual change of L1 influence. To achieve these goals in the present study, an equal number of congruent and non-congruent collocations were selected. Consistent with the results of the previous studies (Caroli, 1998; Shehata, 2008; Liao, 2010; Peng \& Wang, 2016; Sun \& Chen, 2017; Sun, 2018), the present study found that Chinese EFL learners were significantly better at the acquisition of collocations with literal translation in Chinese, that is, congruent collocations, than at acquiring collocations that were not cross-linguistically congruent, i.e., non-congruent collocations. Generally, the only difference between congruent and non-congruent collocations lies in whether or not they have an L1 translation equivalent, considering the fact that the words required to judge were all familiar to the learners, so it can be claimed that the better performances of congruent collocations were achieved with the help of L1, and the performances of non-congruent collocations, on the contrary, were perhaps hindered by L1. In other words, L1 does have an impact on acquiring L2 collocations. Besides, the difference in performance existed in all groups of participants differing in academic levels, indicating that L1 influence is stable.

This finding tallies well with a number of previous studies (Elyildirm, 1998; Caroli, 1998; Shehata, 2008; Liao, 2010; Li, 2013; Wei, 2014; Peng \& Wang, 2016; Sun \& Chen, 2017; Sun, 2018), although the tasks and the materials employed in the current study are somewhat different from those used in previous studies. For example, in Shehata's study (2008), an equal number of collocations with Arabic-English equivalency and collocations with no Arabic-English translation equivalents were chosen to design receptive and productive tests. In terms of the tests, one of the differences lies in that Shehata's tests did not provide L1 translations, and the subjects had to rely on the abundant sentence contexts to pick up a proper verb or a proper adjective. The present study, however, offer L1 versions to the participants to make the correct choices. The results in Shehata's study turn out to be the same as the present study, that is, L1 plays a certain role in acquiring L2 collocations. In Peng and Wang's study (2016), which was also conducted in Chinese classroom settings, no sentence contexts were provided, and the learners were required to make immediate judgments as to the acceptability of the presented collocations. The results in their study also showed the same findings. However, one related study conducted by Leśniewska et al. (2007) came to a totally different conclusion that no obvious cross-linguistic influence was detected, and the advanced learners in their study could use L2 independently of their L1. Anyway, most of the studies, to my 
knowledge, have substantiated the important role of L1 in the use and acquisition of L2 collocations.

Theoretically, the well-recognized model, termed as L2 Lexical Representation and Development Model, proposed by Jiang (2000), can shed light on this finding. According to this model, L2 vocabulary acquisition consists of three stages. In the first stage, also known as formal stage, part of L2 lexeme, namely, L2 spelling and/or pronunciation gains entry into L2 mental lexicon, and there is no link between L2 lexical representation and its conceptual representation. The second stage occurs when the L1 lemma, which includes semantic and syntactic content of L1, is copied into the L2 lexical entry, and this part of content mediates L2 word use. The conceptual representation is likely to be accessed via L1 lemma. With sufficient exposure to L2, the L1 lemma will be replaced by its L2 counterpart, and all content related to L2 is integrated into the lexical entry. This is the final stage where the link between L2 lexical representation and conceptual representation is established. In theory, if given rich contextualized input, the learners can fully master the L2 knowledge. However, most learners will fossilize at the second stage, that is, L1 lemma mediated stage, especially in classroom instruction settings where there is normally a lack of sufficient contextualized input. In other words, the role of L1 will run through nearly the whole process of L2 learning and use. When acquiring L2 congruent collocations, the learners may activate the corresponding L1 knowledge already stored in their mental lexicon, and establish a stable connection between L2 form and L1 concept. With an increasing amount of L2 input, the connection will be strengthened, and finally, they can reach a high degree of automaticity in producing congruent collocations. However, acquiring non-congruent collocations in L2 is totally different, because learners cannot use their ready-made L1 knowledge. They should firstly block the interference from L1 knowledge and realize that they cannot just link the L2 form with L1 knowledge directly. Then, a lot of cognitive resources, such as attention, are needed to establish the correct link between L2 form and its unique concept, also known as conceptual restructuring (Wolter, 2006). Therefore, the acquisition of non-congruent collocations requires much more efforts than acquiring congruent ones. For instance, when acquiring heavy traffic (yong ji de jiao tong), the Chinese learners need to know that yong ji cannot be directly translated into busy (blocking L1 knowledge), but that heavy is the correct word choice (re-establishing form-meaning link).

Since L1 is constantly at play when learners acquire their L2, some researchers argue that congruent collocations can go unheeded in classroom teaching because the learners will automatically acquire them with the help of L1 (Bahns \& Eldaw, 1993). However, the present study revealed that the accuracy rate of congruent collocations was not $100 \%$, accounting for $90 \%$ at both reception and reception level. This means that the learners still struggled with some of these congruent collocations. In Shehata's study (2008), some participants expressed uncertainty about some collocations with Arabic-English congruence, such as take action, white lie and last chance, and as a result, they left these blanks empty or provided wrong answers. In this study, when asked to express modern society, a few participants produced todays' society $(3.13 \%)$, recent society $(3.13 \%)$ and nowadays society $(12.5 \%)$ instead. Therefore, it is of necessity to distinguish the congruent items from the non-congruent ones first, and then treat them differently. Special attention should be paid to non-congruent collocations, and at the same time, congruent collocations should not be neglected.

More importantly, the results in current research indicated that with an increase in exposure to L2 (from freshman to sophomore), L2 collocation knowledge was developed in parallel. This is in line with the findings derived from previous studies (Liao, 2010; Sun \& Chen, 2017). For example, in Liao's study (2010), performances in collocation were elicited from two instruments, multiple choice test and judgment test. The participants from three proficiency level attended these tests. The results revealed that in comparison with the other groups, the advanced group of learners scored higher on both congruent and non-congruent collocations. The result can also be interpreted by L2 Lexical Representation and Development Model proposed by Jiang (2000). According to his model, lexical development is influenced by encounter frequency or exposure. The more frequently a word is encountered, the more mature this word can be developed, that is, the more lexical contents it will contain, especially those at semantic or syntactic level. In this study, participants in sophomore group received a higher score than freshmen in congruent collocations in the production test. Given the fact that sophomores had more exposure to L2, they might also have higher encounter frequency of these collocations. According to Jiang's theory (2000), in this case, more L1 lemma may be copied into the learners' mental lexicon and the connection between L2 form and L1 knowledge is likely to be stronger. Therefore, they are able to retrieve those collocations accurately. For the non-congruent collocations, there were significant differences between freshmen group and sophomore participants on two different tests. Similarly, sophomore participants might receive more exposure to those collocations, so more L1 lemma might be replaced by L2 lemma, or more L2 collocation knowledge underwent conceptual restructuring, linking L2 form to its unique concept. For this reason, the participants in sophomore group with more L2 exposure showed better performance on 
non-congruent collocations.

However, it is noticeable that from sophomore to junior group, the performances on three types of collocational knowledge remained unchanged, or even a decreasing pattern emerged on congruent collocations in the reception test, despite an increase in the exposure to L2. The lack of a significant effect found in congruent collocation in production test may be partially ascribed to a possible ceiling effect. The participants in sophomore and junior group in the current study obtained $98 \%(11.76 / 12)$ and $95 \%(11.40 / 12)$ of the total score. However, in reception congruent collocation test, a slight downward trend was observed. This is not surprising, because the participants at sophomore stage already mastered $96 \%(11.51 / 12)$ of congruent collocations at reception level, approaching the ceiling. Perhaps the developmental plateau occurring from sophomore to junior on non-congruent collocations at both reception and production level are well worth noting. This pattern is likely accounted for by a dearth of contextualized input, i.e. the quality (not the quantity) of the language input they received. A close examination of their learning program can reveal that the periods from freshman to sophomore stage put great emphasis on English basic skills, and they have to sit the Test-for-English-Majors (Band 4) test at the end of the second year, a test that mostly aims at assessing their reading and writing proficiency. Due to the magnitude of and the weight assigned to this test, among other things, quite a few courses, such as intensive reading, listening and writing courses, are included in the program, in order to provide a rich and contextualized source of language input. However, in their third year, a more advanced stage, the focus is diverted from intensive language skill training to specialized courses, like linguistics and literature, which presumably do not place a premium on general-purpose language training. This may largely explain the steady state of the collocation knowledge at the junior stage.

Based on the findings from the current study, implications for teaching and learning collocations can be generated. Firstly, since it is again confirmed in the present study that L1 is an ever-existent factor that can influence L2 learning, it is impractical if the L2 teachers completely ignore the role of L1, especially at the initial stage of leaning. Therefore, it is of great importance to compare the foreign language the learners have been acquiring and their first language, and then draw some meaningful differences. These different items or structures should be paid extra attention. For example, in the present study, non-congruent collocations should receive more attention as they are more prone to L1 negative influence, thus leading to more errors. However, congruent collocations should not be neglected, because the learners will still make mistakes on them. Secondly, exposure to sufficient amounts of L2 in a contextualized situation is very important. Without enough authentic language input, it may not be likely to strengthen the link between form and meaning (congruent collocations) and re-establish this link (non-congruent collocations).

\section{Conclusion}

The current study investigated the reception and production of L2 congruent and non-congruent collocations among Chinese EFL learners, and more importantly, it also examined the effect of L2 exposure on learning L2 collocations, by administering an acceptability judgement test and a blank-filling test of collocations. The results indicated that irrespective of L2 exposure, congruent collocations were better mastered than non-congruent collocations, suggesting that the learners' L1 has a lasting effect on L2 collocation learning. Besides, with L2 exposure increasing, collocation knowledge was developed first, and then remained unchanged or even decreased. This suggests that L1 influence does not necessarily change as learners receive more exposure to L2. Therefore, L2 exposure does not always modulate the influence of L1 on the acquisition of L2 collocations among EFL learners.

Admittedly, this study is not without limitations. Firstly, there were three groups of learners involved in this study and it did not control for individual difference factors which were assumed to be at play. Future studies may benefit from a within-subject design, i.e., collecting data over an extended period of time from the same batch of participants. Secondly, the short interval between the reception and the production test might to some degree damage the validity of this study, although some measures were taken to avoid this carryover effect. The participants in future studies should be tested at a much longer interval in one experiment or tested separately in two.

\section{Acknowledgments}

This study was financially supported by a grant from Department of Education of Zhejiang Province (grant number: Y201839977). The author is grateful to the reviewers for their insightful comments.

There is no conflict of interest to publish this paper in this journal. 


\section{References}

Bahns, J., \& Eldaw, M. (1993). Should we teach EFL students collocations? System, 21(1), 101-114. https://doi.org/10.1016/0346-251X(93)90010-E

Benson, M., Benson, E., \& Ilson, R. (1986). The BBI Combinatory Dictionary of English. Amsterdam: John Benjamins Publishing Company. https://doi.org/10.1075/z.bbi1(1st)

Caroli, M. T. (1998). Relating collocations to foreign language teaching. Unpublished doctoral dissertation. University of Reading, England, U.K.

Cowie, A. P. (2002). English dictionaries for foreign learners: A history. Oxford: Oxford University Press.

Ellis, N. (1996). Sequencing in SLA: phonological memory, chunking and points of order. Studies in Second Language Acquisition, 18(1), 91-126. https://doi.org/10.1017/S0272263100014698

Elyildirm, S. (1998). The acquisition of collocations by Turkish learners. Unpublished doctoral dissertation. University of Reading, England, U.K.

Firth, J. R. (1957). Papers in Linguistics 1934-1951. Oxford: Oxford University Press.

Ganji, M. (2012). On the effect of gender and years of instruction on Iranian EFL learners' collocational competence. English Language Teaching, 5(2), 123-133. https://doi.org/10.5539/elt.v5n2p123

Gitsaki, C. (1999). Second Language Lexical Acquisition: A Study of the Development of Collocational Knowledge. Maryland: International Scholars Publications.

Howarth, P. (1996). Phraseology in English Academic Writing: Some Implications for Language Learning and Dictionary Making. Tübingen: Niemeyer. https://doi.org/10.1515/9783110937923

Huang, K. (2015). More does not mean better: Frequency and accuracy analysis of lexical bundles in Chinese EFL learners' essay writing. System, 53, 13-23. https://doi.org/10.1016/j.system.2015.06.011

Jiang, N. (2000). Lexical representation and development in a second language. Applied Linguistics, 21(1), 47-77. https://doi.org/10.1093/applin/21.1.47

Kjellmer, G. (1987). Aspects of English collocations. In W. Meijs (Ed.), Corpus Linguistics and Beyond. Amsterdam: Rodopi.

Laufer, B., \& Waldman, T. (2011). Verb-noun collocations in second language writing: A corpus analysis of learners' English. Language Learning, 61(2), 647-672. https://doi.org/10.1111/j.1467-9922.2010.00621.x

Leśniewska, J., \& Witalisz, E. (2006). Cross-linguistic influence and acceptability judgments of L2 and L1 collocations: A study of advanced Polish learners of English. Eurosla Yearbook, 7(1), 27-48. https://doi.org/10.1075/eurosla.7.04les

Liao, E. H. (2010). An investigation of cross-linguistic transfer in EFL learners' phraseology. Alliant International University, California, United States.

McCarthy, M. (1990). Vocabulary. Oxford: Oxford University Press.

Nesselhauf, N. (2003). The use of collocations by advanced learners of English and some implications for teaching. Applied Linguistics, 24(2), 223-242. https://doi.org/10.1093/applin/24.2.223

Peng, W., \& Wang, T. (2016). An empirical study on L1transfer in learning L2 collocations of mental lexicon. Contemporary Foreign Languages Studies, 23, 34-38.

Peters, E. (2015). The learning burden of collocations: the role of interlexical and intralexical factors. Language Teaching Research, 20(1), 113-138. https://doi.org/10.1177/1362168814568131

Shehata, A. K. (2008). L1 influence on the reception and production of collocations by advanced ESL/EFL Arabic learners of English. Unpublished doctoral dissertation. Ohio University, Columbia, United States.

Sun, H. (2004). A corpus-based study of semantic characteristics of adjective collocations in CLEC. Modern Foreign Languages, 27(4), 410-418.

Sun, H. (2018). An empirical study on the development of collocation knowledge among English major students. Journal of Zhejiang International Studies University, 18(1), 53-60.

Sun, H., \& Chen, Z. (2017). L1 transfer effect on the acquisition of L2 collocations: An empirical study. Journal of Dongguan University of Technology, 24(4), 73-79.

Tan, X. (2006). Exploring Chinese English learners' development in the depth of vocabulary: On meaning and 
collocation. Journal of PLA University of Foreign Languages, 29, 50-53.

Wang, D. (2011). Language transfer and the acquisition of English light verb + noun collocations by Chinese learners. Chinese Journal of Applied Linguistics, 34, 107-125. https://doi.org/10.1515/cjal.2011.018

Wolter, B. (2006). Lexical network structures and L2 vocabulary acquisition: the role of L1 lexical/conceptual knowledge. Applied Linguistics, 27(4), 741-747. https://doi.org/10.1093/applin/aml036

Wolter, B., \& Yamashita, J. (2014). Processing collocations in a second language: A case of first language activation? Applied Psycholinguistics, 36(5), 1193-1221. https://doi.org/10.1017/S0142716414000113

Wood, D. (2006). Uses and functions of formulaic sequences in second language speech: An exploration of the foundations of fluency. Canadian Modern Language Review, 63(1), 13-33. https://doi.org/10.3138/cmlr.63.1.13

$\mathrm{Xu}, \mathrm{Y}$., \& Wang, T. (2015). Effects of frequency, congruency and proficiency on the processing of L2 formulaic sequences. Modern Foreign Languages, 38, 376-385.

Yamashita, J., \& Jiang, N. (2010). L1 influence on the acquisition of L2 collocations: Japanese ESL users and EFL learners acquiring English collocations. TESOL Quarterly, 44(4), 647-668. https://doi.org/10.5054/tq.2010.235998

Zheng, L. \& Xiao, Z. (2015). A corpus-based study of collocational use in oral production by Chinese EFL learners. Foreign Language Learning Theory and Practice, 36, 29-36.

\section{Appendix A}

\section{Target Collocations}

\begin{tabular}{llll}
\hline \multicolumn{2}{l}{ Congruent Collocations } & Non-congruent Collocations & \\
\hline Verb-noun & Adjective-noun & Verb-noun & Adjective-noun \\
\hline do homework & black market & have accident & white lie \\
& & *happen accident & *kind lie \\
join club & fast food & make tea & short cut \\
& & *cook tea & *fast cut \\
& & *boil tea & \\
break record & natural resource & take exam & weak tea \\
& & *join exam & *light tea \\
serve people & public opinion & eat/have soup & brown sugar \\
& & *drink soup & *red sugar \\
waste time & modern society & take/have medicine & heavy rain \\
& & $*$ eat medicine & *big rain \\
& & & *huge rain \\
make decision & fresh air & acquire knowledge & heavy traffic \\
& & $*$ learn knowledge & *busy traffic \\
& & $*$ study knowledge & \\
\hline
\end{tabular}

Note. (1) For all the verb-noun collocations, the articles (definite and indefinite) inserted between the two words, if any, are removed.

(2) * indicates L1-induced ill-formed collocations used in reception test, which is supposed to receive a negative response from the participants

\section{Appendix B}

\section{Acceptability Judgment Test}

Instructions: Please judge whether the verb or the adjective in italic form is acceptable or not. If you think it is acceptable, tick $(\sqrt{ })$ the box accordingly, otherwise put a cross $(\times)$ in the box. The Chinese versions of the underlined collocations are provided. You have 10 minutes to complete this task.

Example: He often takes a walk (散步) after supper.

$\nabla$ Correct

$\square$ Not sure

$\square$ Incorrect

1. The big rain（大雨） has caused floods in many parts of the country.

$\square$ Correct $\quad \square$ Not sure $\quad \square$ Incorrect

2. He was riding high in the public opinion（公众意见） polls. 
$\square$ Correct $\quad \square$ Not sure $\quad \square$ Incorrect

3. You can take a fast cut (捷径) across the field.

$\square$ Correct $\quad \square$ Not sure $\quad \square$ Incorrect

4. If you join the club（加入俱乐部）, you have to obey its rules.

$\square$ Correct $\quad \square$ Not sure $\quad \square$ Incorrect

5. I had a whole bowl for breakfast with red sugar (红糖) and cold milk.

$\square$ Correct $\quad \square$ Not sure $\square$ Incorrect

6. Social problems in modern society（现代社会）are fast growing.

$\square$ Correct $\quad \square$ Not sure $\square$ Incorrect

7. You have to eat medicine (吃药) if you are to be cured of the disease.

$\square$ Correct $\quad \square$ Not sure $\quad \square$ Incorrect

8. If you drive like that, sooner or later you'll happen an accident. (发生事故)

$\square$ Correct $\quad \square$ Not sure $\square$ Incorrect

9. Some of the valuable things were stolen and then sold on the black market.（黑市）

$\square$ Correct $\quad \square$ Not sure $\square$ Incorrect

10. He did very well, but failed to break the record. （打破纪录）

$\square$ Correct $\quad \square$ Not sure $\square$ Incorrect

11. A public servant is supposed to serve people（服务人民） without having any personal gains.

$\square$ Correct $\quad \square$ Not sure $\square$ Incorrect

12. I don't want to waste time（浪费时间） on what seems to be unimportant.

$\square$ Correct $\quad \square$ Not sure $\square$ Incorrect

13. Are you supposed to do homework（做作业） every day?

$\square$ Correct $\quad \square$ Not sure $\quad \square$ Incorrect

14. She was late for the party because of the crowded traffic. (交通拥挤)

$\square$ Correct $\quad \square$ Not sure $\quad \square$ Incorrect

15. It's not right to make a decision（做决定） without investigation and study.

$\square$ Correct $\quad \square$ Not sure $\quad \square$ Incorrect

16. It is polite to drink soup（喝汤）without making a noise.

$\square$ Correct $\quad \square$ Not sure $\quad \square$ Incorrect

17. Exercise, fresh air（新鲜的空气) and good posture are all helpful to our health.

$\square$ Correct $\quad \square$ Not sure $\square$ Incorrect

18. In order not to make him sad, she hid the truth and told a kind lie. (善意的谎言)

$\square$ Correct $\quad \square$ Not sure $\quad \square$ Incorrect

19. They are looking at ways of reducing the waste of natural resources. (自然资源)

$\square$ Correct $\quad \square$ Not sure $\quad \square$ Incorrect

20. It was her job to cook tea（泡茶） three times a day.

$\square$ Correct $\quad \square$ Not sure $\square$ Incorrect

21. You'd better drink some light tea.（淡茶）

$\square$ Correct $\quad \square$ Not sure $\square$ Incorrect

22. Normally, one feels nervous before joining an exam. (参加考试) 
$\square$ Correct $\quad \square$ Not sure $\quad \square$ Incorrect

23. He serves as a waiter at the fast food (快餐) restaurant nearby.

$\square$ Correct $\quad \square$ Not sure $\quad \square$ Incorrect

24. Students can learn a lot of knowledge（学到很多知识）if they take part in these activities.

$\square$ Correct $\quad \square$ Not sure $\quad \square$ Incorrect

\section{Appendix C \\ Blank-filling Test}

Instructions: There is ONLY ONE word missing in each blank. Please put in each blank a proper verb or adjective that best completes each collocation, according to the Chinese version. You have 10 minutes to complete this task.

Example: Just watch what will happen when I press the button. (按键)

1. There is no cut (捷径) to economic recovery.

2. There are a variety of sugars, but_sugar (红糖) is my favorite.

3. If you jump red lights like that, I am sure you will an accident!（发生事故）

4. Liu Xiang is a famous star, and he the record (打破纪录) for several times.

5. There are a lot of ways to have fun, such as playing volleyball, in society. (现代社会)

6. She_time（浪费时间） much time in watching soaps on TV.

7. The_rain (大雨) frustrated our plan for a picnic in the local park.

8. After the club (加入俱乐部), you can enjoy lots of equipment for free.

9. Before going to bed, you are supposed to homework（做作业） for half an hour.

10. You can buy a lot of useful things in market (黑市) at a low cost, such as second-hand books.

11. He returned to his village with the purpose of the people (为人民服务) there after graduation.

12. Nowadays, students are able to knowledge（学习知识) on many online platforms.

13. The newcomer is still not used to the traffic (交通繁忙) in this city, even though they have lived here for three years.

14. It is extremely hard to a decision（做决定） because you have a lot to think about.

15. lie (善意的谎言) is a harmless or small lie you tell to avoid hurting someone.

16. In China, women often soup (喝汤) after giving birth to a baby, especially chicken soup.

17. In this town, people can no longer breathe factories causing much pollution.

18. Students need to an exam (参加考试) for each course in college.

19. Tom is a real fan of Chinese tea. He tea (泡茶) every day.

20. If they waste resources (自然资源) without anyone stopping them, all will be used up in two years.

21. opinion（公众意见） will be taken seriously when the villagers elect their new leader.

22. I do not like the smell of this kind of tea. Instead, I love tea (淡茶), so add some water.

23. If you do not medicine (吃药) in time, you will get even worse.

24. food (快餐) is very popular at noon, because people barely have any time. 


\section{Appendix D}

\section{Word Recognition Test}

Instructions: The followings are some frequently used English words. Please judge whether they are familiar to you, and cross the words that you have no knowledge of.

\begin{tabular}{|l|l|l|l|l|l|}
\hline black & make & eat & \\
\hline do & & take & & natural & \\
\hline break & & fast & & fresh & \\
\hline white & & modern & & have & \\
\hline public & join & & weak & \\
\hline acquire & serve & & brown & \\
\hline heavy & short & & waste & \\
\hline
\end{tabular}

\section{Appendix E}

\section{Background Information}

Please provide the following biographic information. It is for the research purpose ONLY.

Gender Age Major

My first language and foreign language

I have spent years learning English

Any oversea studying experience $\square$ Yes $/ \square$ NO

\section{Copyrights}

Copyright for this article is retained by the author, with first publication rights granted to the journal.

This is an open-access article distributed under the terms and conditions of the Creative Commons Attribution license (http://creativecommons.org/licenses/by/4.0/). 